\title{
An Adjoint-Based Forecast Impact from Assimilating MISR Winds into the GEOS-5 Data Assimilation and Forecasting System
}

\author{
KeVin J. Mueller AND JunJie LiU \\ Jet Propulsion Laboratory, California Institute of Technology, Pasadena, California \\ Will MCCARTy AND Ron GELARO \\ NASA Goddard Space Flight Center, Greenbelt, Maryland
}

(Manuscript received 1 March 2017, in final form 7 August 2017)

\begin{abstract}
This study examines the benefit of assimilating cloud motion vector (CMV) wind observations obtained from the Multiangle Imaging SpectroRadiometer (MISR) within a Modern-Era Retrospective Analysis for Research and Applications, version 2 (MERRA-2), configuration of the Goddard Earth Observing System-5 (GEOS-5) model data assimilation system (DAS). Available in near-real time (NRT) and with a record dating back to 1999, MISR CMVs boast pole-to-pole coverage and geometric height assignment that is complementary to the suite of atmospheric motion vectors (AMVs) included in the MERRA-2 standard. Experiments spanning September-November of 2014 and March-May of 2015 estimated relative MISR CMV impact on the 24-h forecast error reduction with an adjoint-based forecast sensitivity method. MISR CMV were more consistently beneficial and provided twice as large a mean forecast benefit when larger uncertainties were assigned to the less accurate component of the CMV oriented along the MISR satellite ground track, as opposed to when equal uncertainties were assigned to the eastward and northward components as in previous studies. Assimilating only the cross-track component provided $60 \%$ of the benefit of both components. When optimally assimilated, MISR CMV proved broadly beneficial throughout the Earth, with the greatest benefit evident at high latitudes where there is a confluence of more frequent CMV coverage and gaps in coverage from other MERRA-2 wind observations. Globally, MISR represented $1.6 \%$ of the total forecast benefit, whereas regionally that percentage was as large as $3.7 \%$.
\end{abstract}

\section{Introduction}

Atmospheric motion vectors (AMVs), a proxy measure of wind, are indispensable to regional and global numerical weather prediction (NWP) models and analyses. Derived from tracking cloud or water vapor features in satellite imagery, AMVs fill some critical conventional observation data gaps (e.g., the Arctic, Antarctic, and global oceans). However, there remain regions where wind observations are sparse or unavailable, notably in the high-latitude band $\left(55^{\circ}-65^{\circ} \mathrm{N} / \mathrm{S}\right)$ between AMVs obtained from regular geosynchronous (GEO) instrument imagery and those obtained from consecutive orbits of low Earth orbit (LEO) instruments. AMVs from composite LEO-GEO (e.g., Lazzara et al. 2014) and from constellations of LEO instruments (e.g., Borde et al. 2016) increasingly, but not entirely, mitigate these gaps. AMVs from LEO are also

Corresponding author: Junjie Liu, junjie.liu@jpl.nasa.gov limited at low levels (pressures $>700 \mathrm{hPa}$ ) by concerns about the accuracy of the radiometric heights assigned there, which have led multiple NWP centers to exclude low-level AMVs from operational assimilation (Salonen et al. 2015). Cloud motion vector wind observations derived from the Multiangle Imaging SpectroRadiometer (MISR) instrument on board the polar-orbiting Terra satellite could help mitigate the above-coverage gaps (Mueller et al. 2013a,b), since their heights are retrieved by geometric techniques and their coverage is nearly global and concentrated in the lower troposphere.

MISR measures reflected solar radiation in four bands from on board the sun-synchronous Terra satellite at nine distinct viewing zenith angles including nadir $\left(0^{\circ}\right)$ and four angles $\left(26^{\circ}, 46^{\circ}, 60^{\circ}\right.$, and $\left.70^{\circ}\right)$ distributed alongtrack both forward and aft relative to Terra's flight direction. The motion and height of underlying cloud features are obtained from a single MISR overpass by tracking their progression within 275-m resolution, 380-km swath width 
red band imagery over the 3.5-min interval between the initial $70^{\circ}$ forward view and nadir, and then again for the same interval between nadir and the final $70^{\circ}$ aft view (Horváth and Davies 2001; Mueller et al. 2013a,b). Aside from the nadir and $70^{\circ}$, a third view angle of $26^{\circ}$ is necessarily used to differentiate between parallax and along-track cloud motion. This approach yields a precise geometric height and cross-track wind component, but a relatively less precise along-track wind that is sensitive to the accuracy of feature tracking and georegistration (Horváth and Davies 2001). The MISR wind height, cross-track, and along-track components have respective precision of $190 \mathrm{~m}, 1.1 \mathrm{~m} \mathrm{~s}^{-1}$, and $1.8 \mathrm{~m} \mathrm{~s}^{-1}$ (Horváth 2013). The retrieval algorithm is attuned to stratocumulus, frequently tracking them despite the presence of overlying clouds with less distinct texture. As a result, the overwhelming majority ( $>95 \%$ ) of MISR CMV sampling is found at low levels, and sampling is far better over ocean than land.

The geometric heights assigned to MISR CMVs are not prone to the significant difficulties with radiometric heights assigned to other AMVs, which are recognized as a key limitation to their forecast benefit ( $\mathrm{Su}$ et al. 2012). AMV height uncertainty accounts for $70 \%$ of vector wind differences between other types of AMV and rawinsonde. Particularly uncertain are low-level radiometric heights (pressures $>700 \mathrm{hPa}$ ) assigned to broken or semitransparent clouds or in regions where the temperature lapse rate is small (e.g., polar regions) or inverted (e.g., the marine boundary layer). In the arctic, where these conditions are typical, low-level AMVs are deemed unreliable (Key et al. 2003; Santek 2010). In comparisons with AMVs derived from the Geostationary Operational Environmental Satellite (GOES), MISR CMVs have been shown to have less biased heights in the $800-600-\mathrm{hPa}(\sim 2-4-\mathrm{km}$ height $)$ range (Mueller et al. 2017), consistent with similar findings of AMV height bias relative to reanalysis (Salonen et al. 2015). At the same time, MISR CMV heights are prone to uncertainty distinguishing parallax from along-track motion, leading to correlation of error in these components and tendency to overestimate the heights of upper-level [ $>300 \mathrm{hPa}(\sim 7 \mathrm{~km})] \mathrm{CMVs}$, though these comprise less than $5 \%$ of total CMV sampling (Mueller et al. 2017).

Several studies have provided preliminary evaluations of the forecast benefit MISR winds might provide. The first of these studies, Baker et al. 2014, employed an adjoint method to quantify the reduction of 24-h forecast errors from assimilating MISR CMV among a suite of additional observations with the Navy Global Environmental Model (NAVGEM) 4D-Var data assimilation system. They found that MISR winds reduced 24-h global forecast errors, attributing much of that error reduction to lessening a relative dearth of low-level wind observations assimilated by their model. Yamashita (2014) tested assimilation of MISR CMV in addition to routine observations within the 4D-Var NWP system of the Japan Meteorological Agency, and found increased forecast skill over all. Cress (2014) assimilated MISR CMV within the operational 3D-Var numerical weather prediction (NWP) system of the German Weather Service for the summer and winter of 2010, finding a benefit to the anomaly correlation of $500-\mathrm{hPa}$ geopotential heights between forecast and analysis.

These previous studies directly assimilated zonal and meridional components of MISR CMV retrievals, with no explicit mechanism to capitalize on the greater accuracy of the cross-track components of winds reported by MISR. In this study, we have decomposed MISR CMV into along-track and cross-track in order to assign appropriate uncertainties to each component and also explored the impact of assimilating only the more accurate cross-track component. Complementing earlier studies, we evaluate the forecast impact of MISR CMV using the Modern-Era Retrospective Analysis for Research and Applications, version 2 (MERRA-2), 3DVAR configuration of the Goddard Earth Observing System-5 (GEOS-5) data assimilation system (DAS) (Gelaro et al. 2017).

The remaining sections are organized as follows: section 2 describes the datasets, experiments and diagnostic tools used to assess MISR winds benefit to the analysis and forecast. Section 3 summarizes the results, including comparison of techniques and parameters for assimilating MISR winds. Section 4 provides discussion and conclusions.

\section{Data and methods}

\section{a. Review and use of MISR CMV products}

Two distinct sources of MISR CMVs are employed in this study, the monthly aggregated MISR Level 3 CMV product and the Level 2 NRT CMV product. The two products are available online and respectively tagged as MI3MCMVN and MI2TC_CMV_HDF_NRT at the NASA Langley Distributed Active Archive Center. The former is available with 24-h latency archived back to 2000 , the latter with NRT latency (95\% of CMVS in under $2.5 \mathrm{~h}$ ) archived 30 days back from present. Excluded from this study are two other MISR products containing CMV less suitable for assimilation. The MISR Level 2 cloud product (tagged MIL2TCSP) contains a superset of CMV from the Level $3 \mathrm{CMV}$ product that includes retrievals of lower quality. The MISR Level 2 stereo product (tagged MIL2TCST) contains less accurate CMV retrieved by a legacy algorithm. 
The Level 2 NRT CMV product uses the same retrieval and quality control algorithms as the standard Level 3 CMV product, generating results comparable to the latter. However, the two products have minor differences owing to differences between the NRT and standard processing (STD) versions of upstream Level 0 (L0) and Level 1 (L1) data inputs. The NRT software pipeline is applied to incoming L0 instrument and satellite data in sessions associated with as little as $5 \mathrm{~min}$ of data, whereas the standard pipeline operates on the same data consolidated into sessions composing one full orbit $(90 \mathrm{~min})$. Without this consolidation, NRT processing is subject to lost coverage associated with gaps in the availability of necessary inputs at time of processing. Additionally, the continuously updated record of corrections to camera pointing used to perform in-flight geometric calibration is sensitive to the differences between NRT and STD processing. Calibration discrepancies are responsible for a root-mean-square-vector-difference (RMSVD) of $3 \mathrm{~m} \mathrm{~s}^{-1}$ between collocated Level 2 NRT CMVs and Level 3 CMVs (Mueller et al. 2013b).

\section{b. GEOS-5 model, assimilation system, and adjoint methodology}

This study employs version 5.13.0 of the GEOS-5 DAS, with revisions to support MISR winds assimilation and determination of adjoint sensitivity. Version 5.13.0 is associated with officially released GEOS-5 data products between 20 September 2014 and 1 May 2015. The C180 (1/2 latitude-longitude) grid with 72 layers between the surface and $0.01 \mathrm{hPa}$ is employed, with default version 5.13.0 model parameters and assimilated observations (other than MISR CMV) defined by the MERRA-2 reanalysis (Gelaro et al. 2017). MERRA-2 incorporates a broad range of observations, including geostationary AMVs from GOES.

The meteorological analysis in GEOS-5 uses the Gridpoint Statistical Interpolation analysis system (GSI) 3D-Var (Wu et al. 2002; Purser et al. 2003a,b) assimilation methods. The objective of the assimilation is to produce an analysis field for which a cost function constructed from the observation-minus-analysis $(O-A)$ residuals is minimized subject to assumed forecast and observation error statistics (Cohn 1997). The GSI performs minimization relative to control variables including streamfunction contribution from wind, unbalanced velocity potential function, unbalanced temperature, unbalanced surface pressure, moisture, cloud water, ozone, and coefficients for the bias correction of the satellite radiance data.

An adjoint sensitivity method is employed to calculate the impact of each individual observation on the shortrange forecast simultaneously, producing results that can be easily aggregated by data type, location, channel, etc. (Gelaro et al. 2007; Zhu and Gelaro 2008; Gelaro et al. 2010). It is the same method used operationally to monitor and evaluate the impact of assimilated observations. Impacts are measured relative to $24-$ and $30-\mathrm{h}$ forecast error differences in total moist energy. The forecast error is measured against analysis state at the verification time, $t=24 \mathrm{~h}$ (Langland and Baker 2004). The 24- and 30-h forecast are initiated at time $t=0 \mathrm{~h}$ and at time $t=-6 \mathrm{~h}$, respectively. The difference between the former and latter forecasts are due to observations assimilated at the analysis time $t=0 \mathrm{~h}$. The method is undertaken for every 6-h time step, facilitating impact assessment of all assimilated observations in each experiment.

\section{c. Experiments}

\section{1) THINNING AND SCREENING METHODS}

MISR CMV are reported with $17.6 \times 17.6$ gridded resolution with vertical coordinates of height relative to Earth's ellipsoid. For this study, the set of CMV reported per time step was thinned such that only one CMV could be assimilated per $100 \mathrm{~km} \times 100 \mathrm{~km} \times 100 \mathrm{hPa}$ volume on a model aligned grid. This thinning included simple transformation of MISR reported geometric height $h$ into pressure coordinates assuming a constant standard atmosphere:

$$
p=p_{s} e^{-k h},
$$

where $k=1.186 \times 10^{-4} \mathrm{~m}^{-1}$ and $p_{s}=1013.25 \mathrm{hPa}$. Note that this height-pressure conversion formula was only used in the thinning process, while the model geometric height and observation height was used in vertical interpolation during data assimilation process. In addition to spatial thinning, MISR CMV with heights reported below model surface elevation or above $15 \mathrm{~km}$ were also excluded. For all the experiments listed in section s2c(3), a gross-error threshold was also applied to screen CMV differing from background state by more than $8.0 \mathrm{~m} \mathrm{~s}^{-1}$.

Quality indicator (QI) values assigned to MISR CMV were given no influence on the uncertainty assigned during assimilation. CMV QI values are a measure of retrieval consistency between neighbors and between redundant forward and aft camera-based estimates. German Weather Service experiments found CMV QI to poorly predict CMV influence on forecast skill (Cress 2014). Consistent with their finding, our own experiments show negligible correlation between per observation MISR CMV forecast impact and QI.

\section{2) AsSIMILATION METHODS, UNCERTAINTY ASSIGNMENT, AND ASSIMILATION EXPERIMENTS}

Table 1 lists model experiments, three of which differ in the way the winds were assimilated and the uncertainty 
TABLE 1. List of experiments, durations, and assimilation methods.

\begin{tabular}{llll}
\hline \hline \multicolumn{1}{c}{ Expt } & Duration of Expt & MISR data product & \multicolumn{1}{c}{ Method of assimilating MISR winds } \\
\hline CONTROL & 2 Sep-1 Dec 2014 & None & None \\
UV & 2 Sep-1 Dec 2014 & MISR L3 CMV & Joint $u$ and $v$ components \\
ATCT & 2 Sep-1 Dec 2014 & MISR L3 CMV & Independent along-track and cross-track components \\
CT & 2 Sep-1 Dec 2014 & MISR L3 CMV & Only cross-track component \\
ATCT_15 & 1 Mar-1 Jun 2015 & MISR L3 CMV & Independent along-track and cross-track components \\
ATCT_NRT & 2 Sep-1 Dec 2014 & MISR NRT CMV & Independent along-track and cross-track components \\
\hline
\end{tabular}

was assigned to each MISR CMV, all sharing the same September-November (SON) time period in 2014. In the first experiment, labeled UV, we assimilate MISR zonal $u$ and meridional wind $v$ directly, the same as the assimilation methods employed in previous MISR wind assimilation studies (e.g., Baker et al. 2014). The uncertainties applied with this method are $3.0 \mathrm{~m} \mathrm{~s}^{-1}$ for the $u$ - and $v$-vector components. The components are not treated independently, so either both components are rejected or neither is during assimilation. In the second experiment, labeled ATCT, each MISR CMV is translated into alongtrack and cross-track components based on viewing geometry that are then assimilated independently with respective uncertainties of 8.0 and $2.0 \mathrm{~m} \mathrm{~s}^{-1}$. This approach takes advantage of the cross-track having greater theoretical accuracy (Horvath and Davies 2001). The assigned uncertainty for the cross-track wind is the same as assessed in validation studies (Horvath 2013; Mueller et al. 2017). The uncertainty of $8.0 \mathrm{~m} \mathrm{~s}^{-1}$ for the along-track MISR CMV is conservative, being set much greater than the global along-track RMS difference relative to GOES $\operatorname{AMV}\left(3.2 \mathrm{~m} \mathrm{~s}^{-1}\right)$ in order to limit the potential influence of along-track bias and regions of greater uncertainty (Mueller et al. 2017). In the third experiment, labeled CT, only the more accurate cross-track wind component is assimilated. Last, a control experiment, labeled CONTROL, was conducted for the same time period, but with no assimilation of MISR CMV.

In addition to the above experiments comparing assimilation methodology, two variations of the ATCT experiment were conducted using the same assimilation approach. The first, labeled NRT, uses the MISR NRT CMV product rather than the MISR L3 CMV product, to compare their relative effectiveness. The second, labeled ATCT15, extends the timespan of our analysis to March-May (MAM) of 2015.

\section{Results and discussion}

\section{a. Overview}

In the following sections, we investigate the performance of three assimilation approaches through comparisons among the CT, UV, and ATCT experiments (section 3b), compare the sampling and net impact of MISR CMV relative to other assimilated observations for the ATCT and ATCT_15 experiments (section 3c), and assess the consistency of MISR CMV sampling and forecast impact between the NRT CMV and the standard processing (section 3d).

\section{b. Sensitivity of forecast impact to three methods of assimilating MISR CMVs}

Comparisons of mean forecast benefit among ATCT, $\mathrm{UV}$, and CT experiments applying distinct assimilation methodologies to the same data inputs demonstrate the superiority of the ATCT approach. As shown in Table 2, the mean impact per 6-h time step contributed by the assimilated MISR CMV was $-25 \pm 18 \mathrm{~mJ} \mathrm{~kg}^{-1}$ for ATCT, roughly twice that of UV and $70 \%$ greater than that of the CT experiment.

Figures 1d-f present observation-minus-forecast (OMF) (6-h forecast) statistics, showcasing negligible OMF bias for assimilated cross-track components of MISR CMV during the ATCT experiment, but with a bias as large as $2.0 \mathrm{~m} \mathrm{~s}^{-1}$ for the along-track component. In the absence of model or observation bias, OMF should be unbiased (e.g., Kalnay 2003). Here, along-track OMF bias follows a

TABLE 2. Overview of experiment statistics.

\begin{tabular}{lcccccc}
\hline \hline \multicolumn{1}{c}{ Label } & $\begin{array}{c}\text { MISR obs } \\
\text { per } 6 \mathrm{~h}\end{array}$ & $\begin{array}{c}\text { MISR obs per } \\
\text { valid orbit }\end{array}$ & $\begin{array}{c}\text { MISR reject obs } \\
\text { per valid orbit }\end{array}$ & $\begin{array}{c}\text { MISR impact per } \\
6 \mathrm{~h}\left(\times 10^{-3} \mathrm{~J} \mathrm{~kg}^{-1}\right)\end{array}$ & $\begin{array}{c}\text { MISR impact per valid } \\
\text { orbit }\left(\times 10^{-3} \mathrm{~J} \mathrm{~kg}^{-1}\right)\end{array}$ & $\begin{array}{c}\text { MISR impact per } \\
\left.\mathrm{obs}^{(} \times 10^{-6} \mathrm{~J} \mathrm{~kg}^{-1}\right)\end{array}$ \\
\hline UV & $6000 \pm 3000$ & $2400 \pm 360$ & $520 \pm 160$ & $-12 \pm 18$ & $-4.8 \pm 10.4$ & $-2.0 \pm 82.5$ \\
ATCT & $6700 \pm 3100$ & $2500 \pm 360$ & $330 \pm 90$ & $-25 \pm 18$ & $-9.5 \pm 8.6$ & $-3.7 \pm 78.8$ \\
CT & $3300 \pm 1600$ & $1300 \pm 180$ & $170 \pm 40$ & $-15 \pm 15$ & $-5.9 \pm 8.3$ & $-4.6 \pm 107.6$ \\
ATCT_15 & $8200 \pm 1900$ & $2500 \pm 350$ & $320 \pm 130$ & $-27 \pm 17$ & $-8.2 \pm 8.2$ & $-3.3 \pm 79.5$ \\
ATCT_NRT & $6000 \pm 2200$ & $1900 \pm 600$ & $240 \pm 120$ & $-21 \pm 15$ & $-6.8 \pm 7.6$ & $-3.5 \pm 78.1$ \\
\hline
\end{tabular}



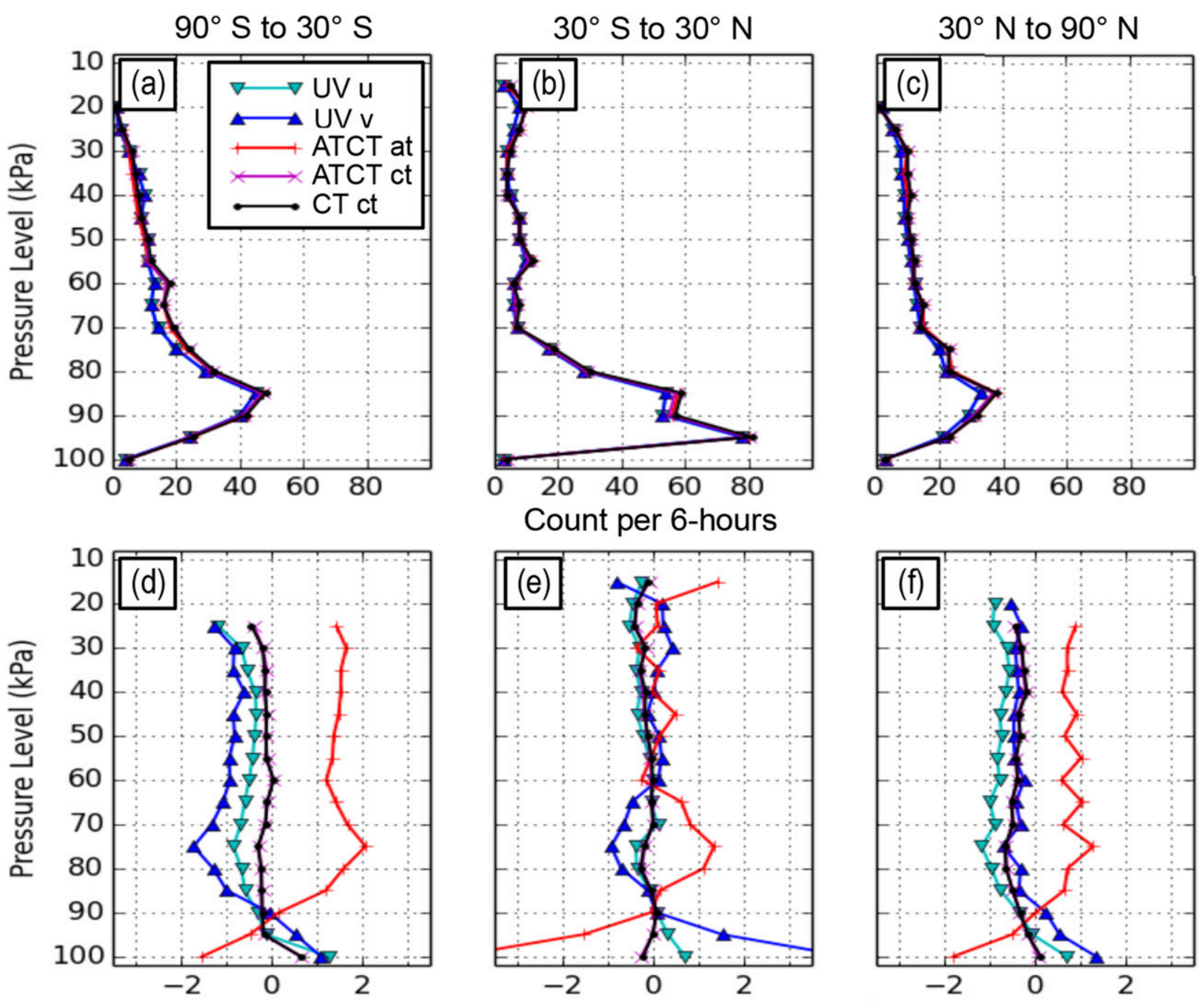

Observation -forecast bias $\left(\mathrm{m} \mathrm{s}^{-1}\right)$
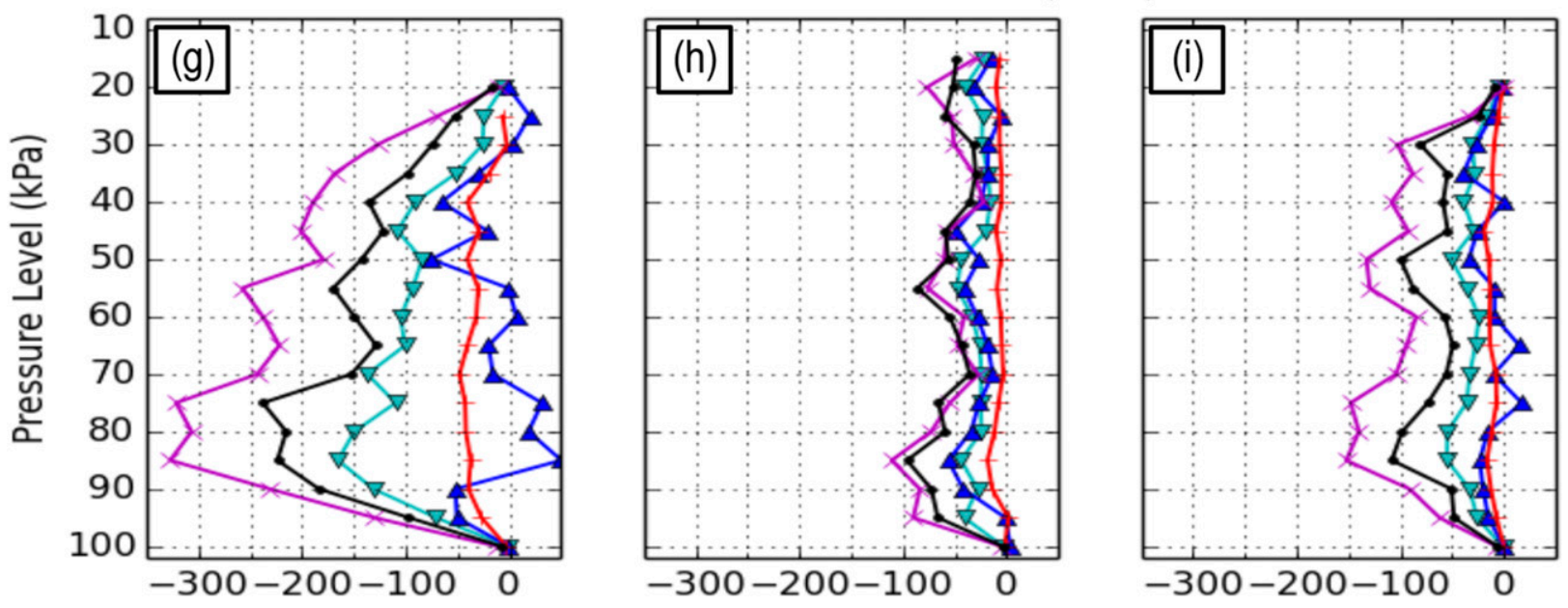

Forecast Impact $\left(\mathrm{J} \mathrm{kg}^{-1} \times 10^{-6}\right)$

FIG. 1. Vertical profiles of per component forecast impact of UV, ATCT, and CT experiments. Vertical profiles for (a),(d),(g) the Southern Hemisphere extratropics; (b),(e),(h) the tropics; and (c),(f),(i) the Northern Hemisphere extratropics are shown for (top) sampling, (middle) observation minus 6-h forecast, and (bottom) forecast impact for the $u$ and $v$ components of MISR CMV in the UV experiment (labeled UV $u$ and UV $v$ in legend); the along-track (ATCT at) and cross-track (ATCT ct) components in ATCT; and the cross-track components (CT ct) in CT. 
Global observation impact by type

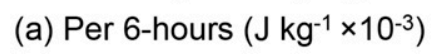

(b) Per observation $\left(\mathrm{J} \mathrm{kg}^{-1} \times 10^{-6}\right)$

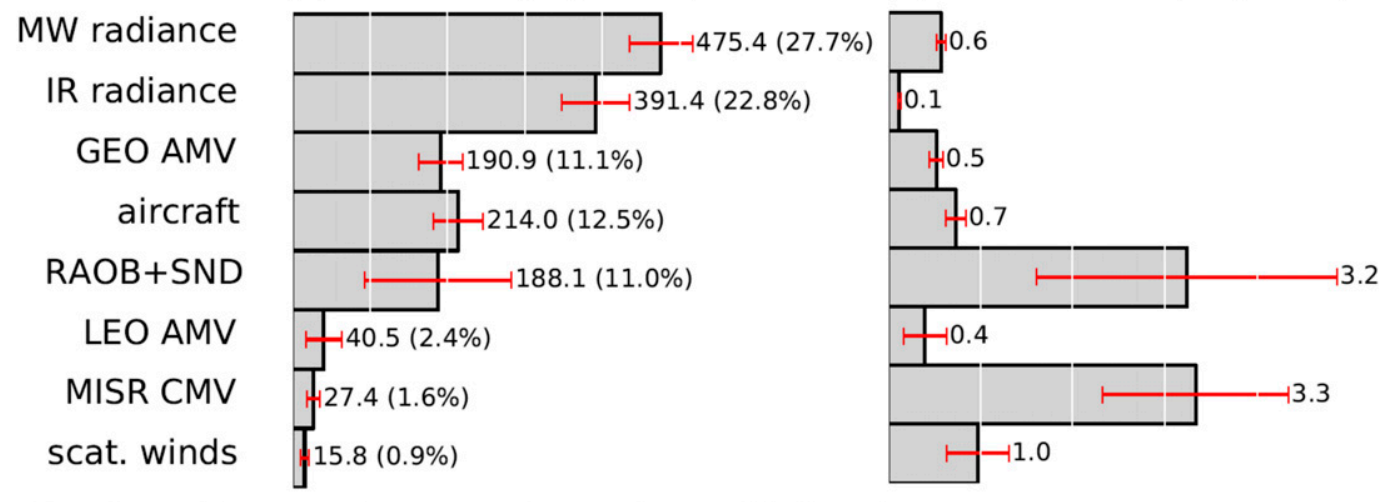

Regional impact by type, for $55^{\circ}$ to $70^{\circ}$ South
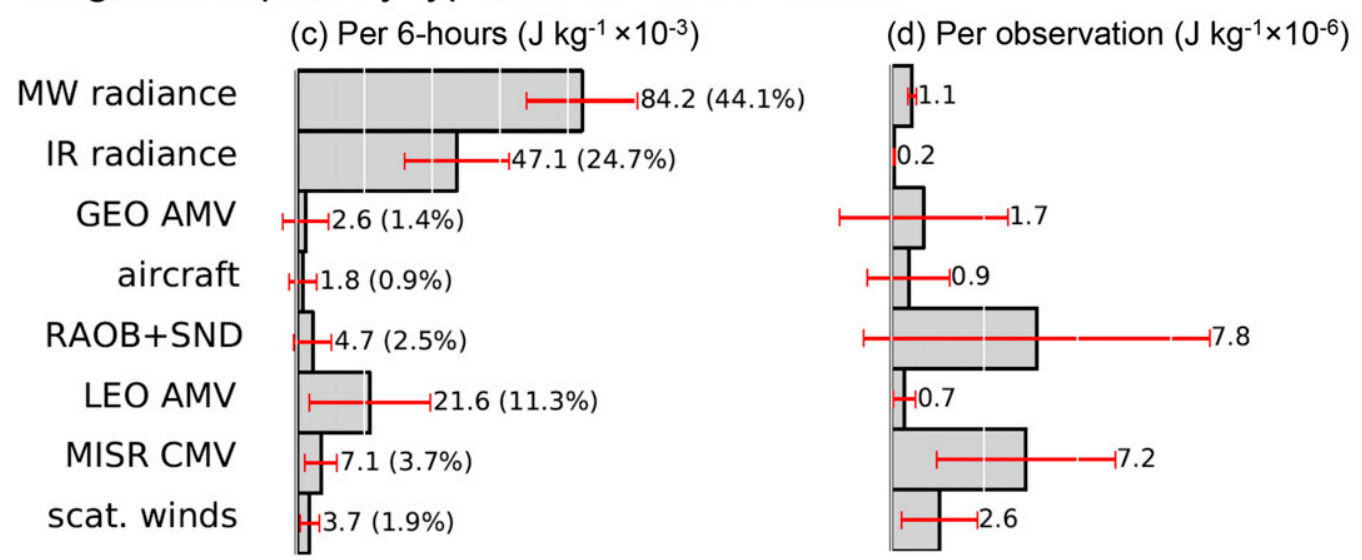

FIG. 2. Forecast impact of various observation types in ATCT and ATCT_15 experiments. (a),(b) The mean 24-h forecast global and (c),(d) a select regional impact for selected types of observations in the ATCT_15 experiments as accumulated (left) per $6 \mathrm{~h}$ and (right) per observation. Error bars representing standard deviations are given alongside percentages of total impact.

pattern broadly consistent with that seen in comparison between MISR CMVs and GOES AMVs (Mueller et al. 2017). The along-track component bias at lower levels (below $750 \mathrm{hPa}$ ) is proportional to height. The bias changes from negative to positive around the peak height of sampling density, at $850 \mathrm{hPa}$ in the top row of Fig. 1. This is a consequence of the correlation between error in the height and error in the along-track component of MISR CMVs causing preferential sampling of negative/positive along-track bias at heights below/ above the peak in sampling. Above $750 \mathrm{hPa}$, MISR CMV along-track bias has no such gradient, instead being consistently on the order of $1-2 \mathrm{~m} \mathrm{~s}^{-1}$ at high latitudes where the majority of sampling is found. Over the tropics, where sampling is sparse, the bias is not evident. Figures 1d-f also show bias profiles for the UV experiment, wherein the same underlying positive along-track bias manifests as a principally southward component bias at low latitudes and both westward and southward bias at mid- to high latitudes.

Evident in Figs. 1g-i, heights and regions where the along-track bias is most pronounced in the ATCT experiment also show the largest discrepancies between UV and ATCT in the forecast error reduction. This is most evident in the southern extratropics where assimilation of the $v$ component in the UV experiment actually degrades the forecast for midlevel CMVs at heights from 900 to $500 \mathrm{hPa}$. In contrast, the along-track component in the ATCT experiment is consistently beneficial. In contrast to the $v$ component, the assimilated $u$ component consistently improves the forecast, but to a far lesser degree than the assimilated cross-track component in the ATCT experiment, which is largely due to the large $u$ component bias (Figs. 1d-f) and random errors relative to cross-track component $\left(2.5 \mathrm{vs} 2.1 \mathrm{~m} \mathrm{~s}^{-1}\right)$. It is also evident in Figs. 1a-c that the same heights and 
(a) MISR CMVs
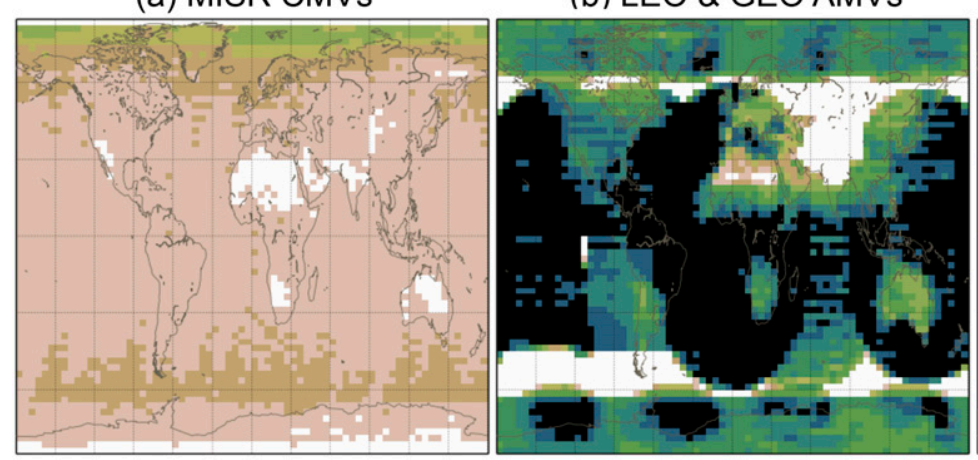

(d) Aircraft

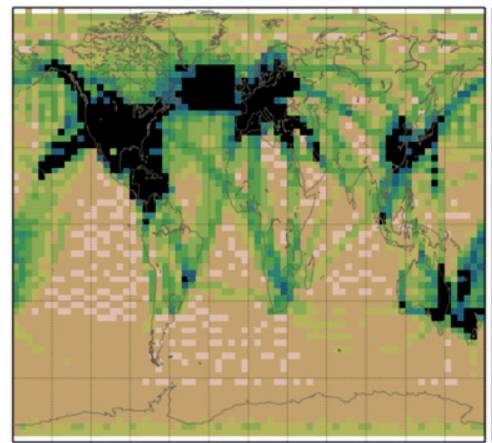

(c) Scatterometer winds

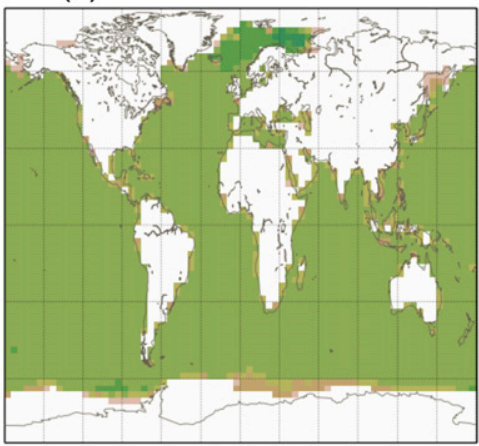

(e) Radiosonde \& dropsonde

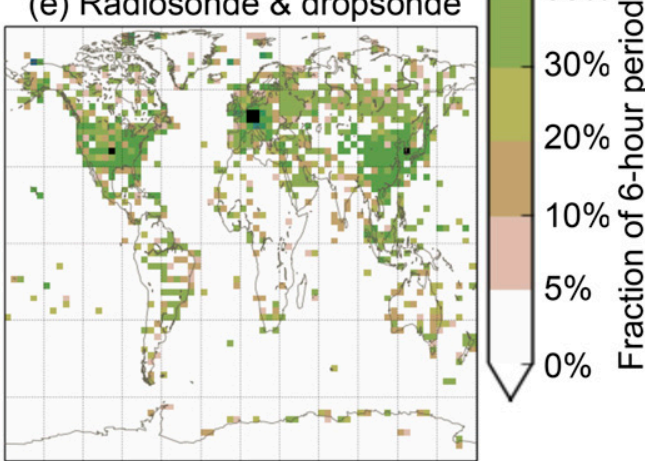

$100 \%$

95\% $90 \%$ $80 \%$.

$70 \%$ 索 $50 \%$ o

$\%$

20\%

它

4

든

FIG. 3. Mapped coverage of MISR CMVs relative to other classes of observation. Mapped coverage for five classes of observations assimilated in ATCT and ATCT_15 experiments spanning September-November 2014 and March-May 2015. Coverage is measured per $2.5^{\circ}$ latitude $\times 2.5^{\circ}$ longitude map grid cell by the fraction of 6 -h periods throughout experiments during which one or more observations were assimilated within that grid cell.

regions where the $v$ component degraded the UV forecast also produced a greater number of rejected CMV in UV relative to ATCT. The northern extratropics exhibit the same trends as above, though to a lesser extent. The trends observed in the tropics represent an instructive counterpoint. Because the mean along-track bias is less consistent and not as large there, and because the projection of cross-track and along-track winds is more aligned with $u$ and $v$ components there, the forecast benefit is roughly equivalent for the ATCT and UV experiments.

For the CT experiment, the along-track component was excluded all together. As evident for all latitude bands (Figs. 1g-i), assimilating CT only consistently reduced the forecast error, but choosing not to assimilate the along-track component had an adverse effect on the benefit provided by the cross-track component, especially over the extratropics, reducing its benefit by as much as $40 \%$. Riishøjgaard et al. (2004) also showed that single wind component assimilation produced a poorer representation of that field in the analysis state. They argued that the analysis accuracy of single wind assimilation depends more on the forecast error covariance specified in data assimilation compared to assimilating two wind components. Stoffelen et al. (2005) and Marseille et al. (2008) also argued that proper background error covariance is essential to maximize single wind observation impact. In CT, we used the same forecast error covariance as in the ATCT case. The poorer performance of CT indicates that the default forecast error covariance does not accurately capture the relationships between different dynamical variables. Since the wind and mass fields, such as pressure, are more tightly coupled over the extratropics in the forecast error covariance, the degradation of assimilating a single component is larger over the extratropics compared to the tropics (Figs. 1g-i).

\section{c. MISR forecast impact relative to other instruments}

The global 24-h forecast impact amongst MISR CMVs and other classes of satellite instruments is compared for the ATCT_15 experiment in Fig. 2a. (The results of the comparable ATCT experiment are roughly equivalent, with minor differences discussed in section 3d.) MISR CMVs represent $1.6 \%$ of the total forecast benefit from all of the observations, while AMVs from low Earth orbit (LEO) and geosynchronous (GEO) represent $\sim 15 \%$. The total impact of satellite winds is 
(a) MISR CMVs

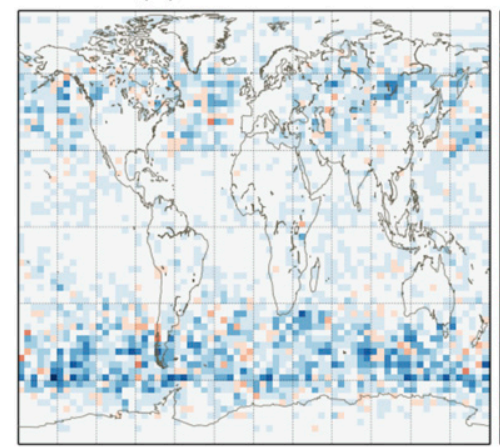

(b) LEO \& GEO AMVs

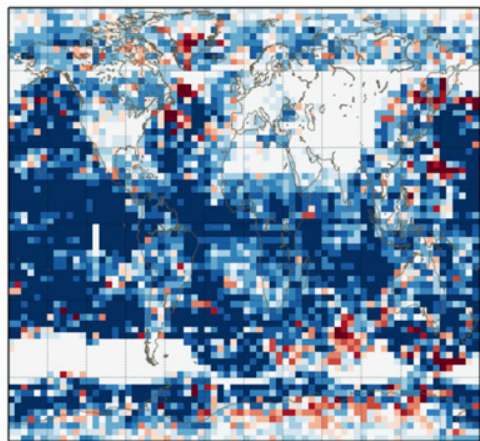

(d) Aircraft

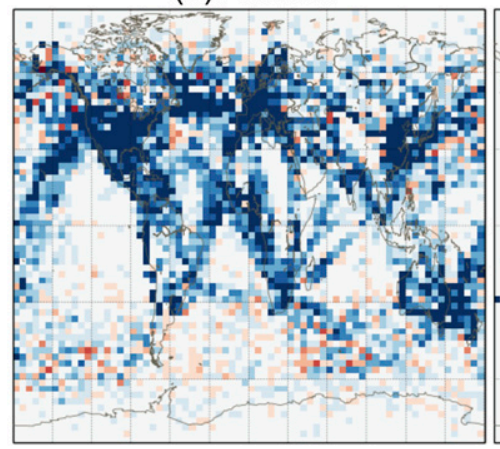

(c) Scatterometer winds

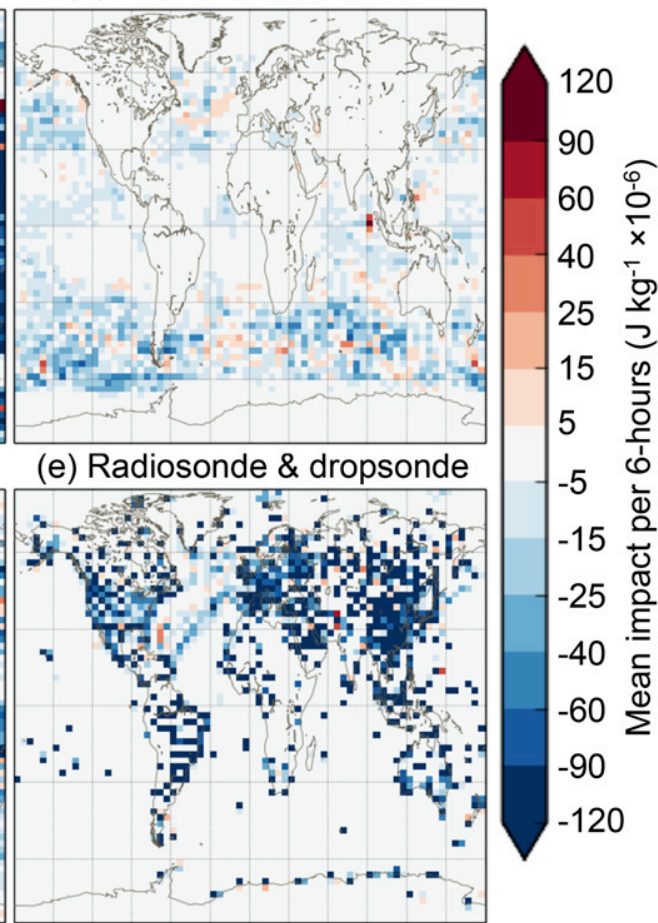

FIG. 4. Adjoint forecast impact of MISR CMVs relative to other classes of observation. As in Fig. 3, but showing mean forecast impact accumulated per 6-h period in each map grid cell.

second behind that of infrared (IR) and microwave (MW) radiance observations, which represent just over $50 \%$. Rawinsonde and dropsonde profiles (labeled raob+SND) and in situ aircraft measurements that include wind, temperature, and pressure each represent another $\sim 12 \%$. Surface wind forcing as measured by microwave scatterometers represent $1 \%$ of impact. An additional $10 \%$ of forecast impact not plotted in Fig. 2a is contributed by various land- and ship-based observations, by radio occultation observations, and by pilotballoon measurements of wind. Figure $2 b$ shows the per observation impact of MISR CMV to be the largest of the above observation groups, with magnitude comparable to raob+SND.

MISR CMVs are broadly beneficial everywhere, with the greatest benefit evident at high latitudes where there is a confluence of more frequent CMV coverage and gaps in coverage from other wind observations. For example, Fig. 2c shows that MISR CMV contributes $3.7 \%$ of the total forecast benefit between latitudes $55^{\circ}$ and $70^{\circ} \mathrm{S}$, more than double that of the global mean forecast impact of $1.6 \%$. Figure 3 shows coverage for classes of wind observations, where coverage is defined by the fraction of 6-h periods during which one or more observation was assimilated within each $2.5^{\circ}$ latitude $\times$ $2.5^{\circ}$ longitude grid cell. Figure 3 a shows the frequency of CMV coverage in the months of SON to be under $10 \%$ at low latitudes, and up to $20 \%$ or $50 \%$ depending on season at high latitudes. MISR CMV coverage is primarily governed by the satellite repeat interval, varying from 9 days at the equator to as little as 90 min near the poles, and by seasonal variation of available sunlight at high latitudes. Greater MISR CMV sampling at high latitudes synergistically coincides with gaps between LEO and GEO AMV coverage evident in Fig. 3b, ultimately producing greater forecast benefit for those regions as evident in Fig. 4a. Over the Southern Ocean, these regions also coincide with a paucity of aircraft and sonde observations (Figs. 3d and 3e), and, correspondingly, even greater forecast benefit. Another region of enhanced MISR CMV benefit (Fig. 4a) is found over central Asia in the gap between GEO AMVs captured from $M e$ teosat- 9 and Multifunction Transport Satellite-2 (MTSAT-2) instruments (Fig. 3b). The region also lacks frequent coverage from aircraft and sondes (Figs. 3e and 3f), to the extent that the rare instances of MISR CMV retrieved there have outsized influence. Over ocean, the geographic distribution of forecast benefit from MISR CMVs is rather similar to that of scatterometer winds, possibly reflecting the fact that both largely or entirely 


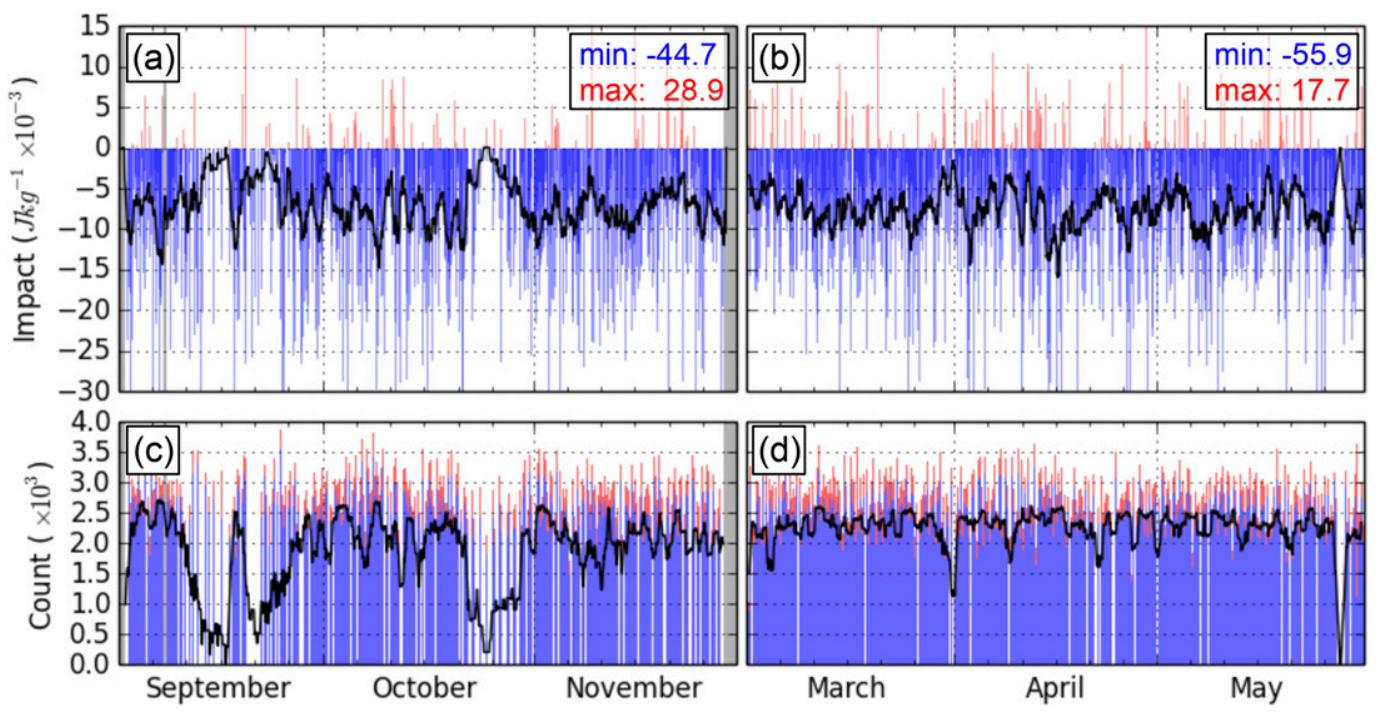

FIG. 5. Time series of MISR CMV sampling and forecast impact per orbit for ATCT and ATCT_15. Time series of (a),(b) forecast impacts and (c),(d) observation counts for MISR CMV data during (left) the ATCT experiment from September to November 2014 and (right) the ATCT_15 experiment from March to May 2015. Orbits with a net negative (i.e., beneficial) forecast impact are indicated in blue, the rest are in red. Minima and maxima are shown in the top right. A running mean over 15 orbits (i.e., $\sim 1$ day) is plotted in black. Numbers of observations per orbit that were assimilated (blue) and rejected (red) are shown alongside a 15-orbit running mean (black).

provide low-level constraints on the wind field (Figs. 3c and $4 \mathrm{c})$. For example, both provide negligible benefit over large swaths of the tropical Pacific and Atlantic Oceans, which is primarily due to the dense wind observations from the default LEO and GEO satellites (Fig. 4b). Although the forecast benefit from MISR CMV is evidently enhanced where coverage from other wind observations is sparse, MISR CMVs also exhibit significant benefits in well-sampled regions such as the North Pacific.

\section{d. Sensitivity of MISR wind forecast impact to assimilation time period and MISR CMV products}

ATCT_15 and ATCT were carried out over two different seasons: boreal summer and fall, respectively. Comparing these two experiments helps identify the sensitivity of MISR wind impact to time of year, while aggregating them provides 6 months of simulation. On a daily basis, MISR CMVs provide a consistent 24-h forecast benefit throughout ATCT and ATCT_15 as indicated in Fig. 5 by a time series of per orbit forecast impact wherein the running mean over 15 orbits (i.e., the rough equivalent of $24 \mathrm{~h}$ ) is always beneficial (i.e., negative contribution to forecast error norm). Measurements of forecast impact are inherently noisy, with the standard deviation of per orbit CMV impact having comparable magnitude to the mean (i.e., $\left.10 \times 10^{-3} \mathrm{~J} \mathrm{~kg}^{-1}\right)$. Still, the overwhelming majority $(88 \%)$ of orbits with MISR CMV sampling are found to provide a net forecast benefit, while the infrequent remainder is broadly distributed, such that no duration of sequential orbits contributes a significant regression. The largest single orbit forecast regression is $28.9 \times 10^{-3} \mathrm{~J} \mathrm{~kg}^{-1}$ during ATCT. As visualized in Fig. 5 and Table 2, the number of MISR CMV assimilated on a per-orbit basis (2500) varies little $( \pm 360)$ in ATCT or ATCT_15. Nor does the number of CMV rejected $(330 \pm 110)$ during computation of model analysis state through incremental minimization of the GSI cost function.

The near equivalence of CMV 6-hourly forecast impacts in ATCT and ATCT_15 is a coincidental byproduct of ATCT producing 16\% greater impact per orbit offset by $25 \%$ fewer orbits producing valid CMV sampling. The greater per-orbit CMV benefit in ATCT can be traced to seasonality of sampling, with ATCT having a greater fraction of total sampling located over the Southern Ocean where the model most benefits from assimilating CMVs. The sampling deficit in ATCT can be traced to two gaps evident in Fig. 5 that were caused by a temporary suboptimal software configuration affecting Terra attitude data that had been used in the MISR standard processing chain during September 2014. The underlying issue, which was identified and rectified in November 2014, did not affect other Terra instruments or MISR science products, and also did not affect MISR NRT processing, hence, the absence of gaps in Fig. 6 corresponding to those evident in Fig. 5. 


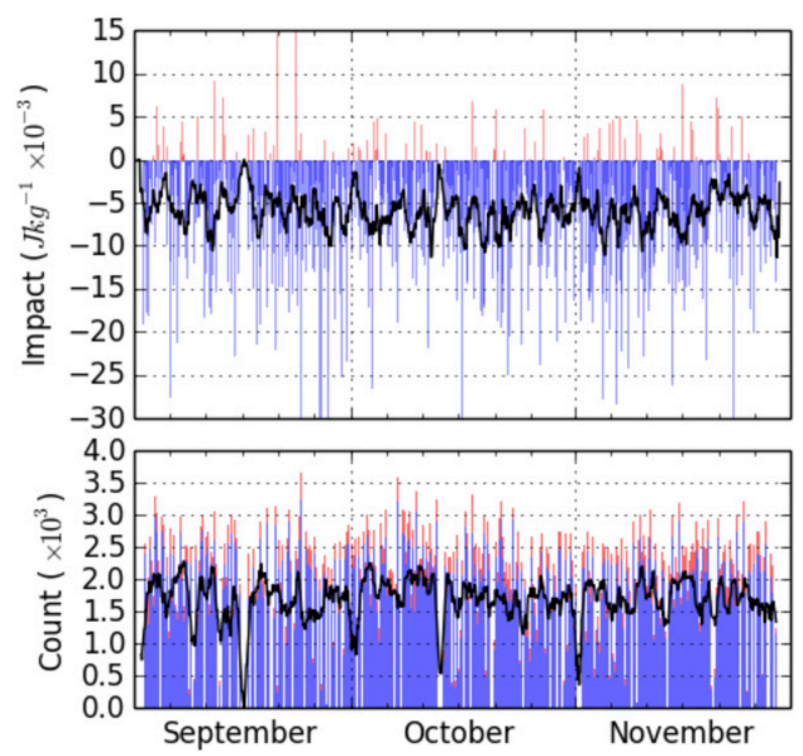

FIG. 6. As in Fig. 5, but for experiment NRT.

Figure 6 shows the time series of the MISR CMVs impact and observation count in the NRT experiment, which assimilates MISR NRT CMVs. Relative to standard processing, the NRT CMVs are prone to losses of sampling due to timeliness of necessary data input. As a result, NRT assimilates fewer samples per orbit (1900) with greater variability of per orbit sampling $( \pm 600)$. Relative to ATCT, the fraction of sampling in NRT $(76 \%)$ is consistent with the fraction of forecast benefit $(72 \%)$ (i.e., 6.8 out of $9.5 \times 10^{-3} \mathrm{~J} \mathrm{~kg}^{-1}$ ). The distribution and magnitude of forecast regressions on a per orbit basis are also comparable to ATCT.

\section{Conclusions}

A series of experiments have been conducted, demonstrating the benefit of assimilating cloud motion vectors from the MISR CMVs over periods covering September-November of 2014 and March-May within the GEOS-5 DAS as determined by an adjoint-based forecast sensitivity method. Whereas previous studies have directly assimilated the zonal and meridional components of MISR CMVs, this study demonstrates more consistently beneficial and twice as large a mean forecast benefit when assimilating along-track and crosstrack components and assigning larger uncertainties to less accurate along-track component. Although the more certain cross-track component contributes more than $90 \%$ of the total forecast benefit when assimilating both along track and cross track, assimilating only the latter provides only $60 \%$ of the forecast benefit as both. Systematic along-track bias in MISR CMVs consistent with earlier studies was evident in OMF statistics. This factored into the benefits of assigning greater uncertainty to the along track. Another approach worth investigating would be application of a height- and possibly latitude-dependent along-track bias correction.

The overall benefit of optimally assimilating MISR CMVs was a $1.6 \%$ contribution to the global reduction of the moist energy error norm for 24-h forecasts, with about twice that percentage of contribution in regions such as the Southern Ocean that are less well observed. Note that the impact on 24-h forecast error reduction is only one measure of the observation impact. The overall reduction on 24-h forecast errors from assimilating MISR winds corroborates earlier studies showing an overall benefit from MISR CMVs as measured by various metrics within multiple models (e.g., Yamashita 2014). The magnitude of benefit is promising in regard to the multiangle retrieval of CMVs, given the limitations on MISR coverage imposed by its relatively narrow 360-km swath. A single wider-swath multiangle imager, a tandem convoy of such imagers (which avoids the ambiguity between parallax and along-track motion), or a multitude of low cost nanosatellite variants could all provide significantly greater forecast benefit.

Acknowledgments. We acknowledge the funding support from NASA data for operational analysis (NDOA) program under Grant 13-NDOA13-0014. We acknowledge the technical support from Joe Stassi (GMAO), Dan Holdaway (GMAO), and Meta Sienkiewicz (GMAO). We appreciate the instructive comments and discussions with Dr. Nancy Baker (NRL), and the support from Dr. Dave Diner (JPL), Veljko Jovanovic (JPL), and Michael Garay (JPL). All the calculations were carried out with the supercomputer from NASA Center for Climate Simulations (NCCS). This research was carried out at Jet Propulsion Laboratory, California Institute of Technology, under contract with the National Aeronautics and Space Administration.

\section{REFERENCES}

Baker, N. L., P. M. Pauley, R. H. Langland, K. Mueller, and D. Wu, 2014: An assessment of the impact of the assimilation of NASA TERRA MISR atmospheric motion vectors on the NRL global atmospheric prediction system. Second Symp. on the Joint Center for Satellite Data Assimilation, Atlanta, GA, Amer. Meteor. Soc., J3.1, https://ams.confex.com/ams/94Annual/ webprogram/Paper231106.html.

Borde, R., O. Hautecoeur, and M. Carranza, 2016: EUMETSAT global AVHRR wind product. J. Atmos. Oceanic Technol., $\mathbf{3 3}$ 429-438, https://doi.org/10.1175/JTECH-D-15-0155.1.

Cohn, S. E., 1997: An introduction to estimation theory. J. Meteor. Soc. Japan, 75, 257-288, https://doi.org/10.2151/jmsj1965.75.1B_257. 
Cress, A., 2014: Assessment of MISR wind vector quality and impact using the global NWP system at DWD. 12th Int. Winds Workshop, Copenhagen, Denmark, EUMETSAT, 7 pp., http://www.eumetsat.int/website/wcm/idc/idcplg?IdcService $=$ GET_FILE\&dDocName=PDF_CONF_P61_S4_02_CRESS_ $\mathrm{V} \&$ RevisionSelectionMethod $=$ LatestReleased\&Rendition $=$ Web

Gelaro, R., Y. Zhu, and R. M. Errico, 2007: Examination of variousorder adjoint-based approximations of observation impact. $\mathrm{Me}$ teor. Z., 16, 685-692, https://doi.org/10.1127/0941-2948/2007/0248.

—, R. H. Langland, S. Pellerin, and R. Todling, 2010: The THORPEX observation impact intercomparison experiment. Mon. Wea. Rev., 138, 4009-4025, https://doi.org/10.1175/ 2010MWR3393.1.

— , and Coauthors, 2017: The Modern-Era Retrospective Analysis for Research and Applications, version 2 (MERRA-2). J. Climate, 30, 5419-5454, https://doi.org/10.1175/JCLI-D-16-0758.1.

Horváth, Á., 2013: Improvements to MISR stereo motion vectors. J. Geophys. Res. Atmos., 118, 5600-5620, https://doi.org/10.1002/ jgrd.50466.

_ and R. Davies, 2001: Feasibility and error analysis of cloud motion wind extraction from near-simultaneous multiangle MISR measurements. J. Atmos. Oceanic Technol., 18, 591-608, https:// doi.org/10.1175/1520-0426(2001)018<0591:FAEAOC >2.0.CO;2.

Kalnay, E., 2003: Atmospheric Modeling, Data Assimilation, and Predictability. Cambridge University Press, $341 \mathrm{pp}$.

Key, J. R., D. Santek, C. S. Velden, N. Bormann, J.-N. Thepaut, L. P. Riishøjgaard, Y. Zhu, and W. P. Menzel, 2003: Clouddrift and water vapor winds in the polar regions from MODISIR. IEEE Trans. Geosci. Remote Sens., 41, 482-492, https:// doi.org/10.1109/TGRS.2002.808238.

Langland, R. H., and N. Baker, 2004: Estimation of observation impact using the NRL atmospheric variational data assimilation adjoint system. Tellus, 56A, 189-201, https://doi.org/10.3402/ tellusa.v56i3.14413.

Lazzara, M. A., R. Dworak, D. A. Santek, B. T. Hoover, C. S. Velden, and J. R. Key, 2014: High-latitude atmospheric motion vectors from composite satellite data.J. Appl. Meteor. Climatol., 53, 534-547, https://doi.org/10.1175/JAMC-D-13-0160.1.

Marseille, G. J., A. Stoffelen, and J. Barkmeijer, 2008: Sensitivity Observing System Experiment (SOSE) - A new effective NWPbased tool in designing the global observing system. Tellus, 60A, 216-233, https://doi.org/10.1111/j.1600-0870.2007.00288.x.

Mueller, K. J., C. M. Moroney, V. Jovanovic, M. J. Garay, J.-P. Muller, L. Di Girolamo, and R. Davies, 2013a: MISR Level 2 Cloud Product Algorithm Theoretical Basis. Tech. Rep. JPL D-73327, Jet Propulsion Laboratory, 51 pp., https:// eospso.gsfc.nasa.gov/sites/default/files/atbd/MISR_L2_CLOUD_ ATBD-1.pdf.

- — - and - 2013b: MISR level 2 cloud product quality statement, September 14, 2012. Atmospheric Science Data Center, 4 pp., https://eosweb.larc.nasa.gov/sites/default/files/ project/misr/quality_summaries/L2TC_Cloud_Product.pdf.
, and Coauthors, 2017: Assessment of MISR Cloud Motion Vectors (CMVs) relative to GOES and MODIS Atmospheric Motion Vectors (AMVs). J. Appl. Meteor. Climatol., 56, 555572, https://doi.org/10.1175/JAMC-D-16-0112.1.

Purser, R. J., W. Wu, D. F. Parrish, and N. M. Roberts, 2003a: Numerical aspects of the application of recursive filters to variational statistical analysis. Part I: Spatially homogeneous and isotropic Gaussian covariances. Mon. Wea. Rev., 131, 1524-1535, https://doi.org/10.1175//1520-0493(2003)131<1524: NAOTAO $>2.0 . C O ; 2$.

,,--- , and,$- 2003 \mathrm{~b}$ : Numerical aspects of the application of recursive filters to variational statistical analysis. Part II: Spatially inhomogeneous and anisotropic general covariances. Mon. Wea. Rev., 131, 1536-1548, https://doi.org/ 10.1175//2543.1.

Riishøjgaard, L. P., R. Atlas, and G. D. Emmitt, 2004: The impact of Doppler lidar wind observations on a single-level meteorological analysis. J. Appl. Meteor., 43, 810-820, https://doi.org/ 10.1175/2091.1.

Salonen, K., J. Cotton, N. Bormann, and M. Forsythe, 2015: Characterizing AMV height-assignment error by comparing best-fit pressure statistics from the Met Office and ECMWF Data Assimilation Systems. J. Appl. Meteor. Climatol., 54, 225-242, https://doi.org/10.1175/JAMC-D-14-0025.1.

Santek, D., 2010: The impact of satellite-derived polar winds on lower-latitude forecasts. Mon. Wea. Rev., 138, 123-139, https:// doi.org/10.1175/2009MWR2862.1.

Stoffelen, A., G. Marseille, E. Andersson, and D. G. Tan, 2005: Comments on "The impact of Doppler wind observations on a single-level meteorological analysis." J. Appl. Meteor., 44, 1276-1277, https://doi.org/10.1175/JAM2268.1.

Su, X., J. Derber, and J. Jung, 2012: Recent work on satellite atmospheric motion vectors in the NCEP data assimilation system. 11th Int. Winds Workshop, Auckland, New Zealand, EUMETSAT., 6 pp., https://www.eumetsat.int/website/ wcm/idc/idcplg? IdcService $=$ GET_FILE\&dDocName=PDF_ CONF_P60_S4_13_SU_V\&RevisionSelectionMethod= LatestReleased \&Rendition $=$ Web.

Wu, W.-S., R. J. Purser, and D. F. Parrish, 2002: Three-dimensional variational analysis with spatially inhomogeneous covariances. Mon. Wea. Rev., 130, 2905-2916, https://doi.org/ 10.1175/1520-0493(2002)130<2905:TDVAWS > 2.0.CO;2.

Yamashita, K., 2014: The impact of NASA TERRA MISR atmospheric motion vector assimilation into JMA's operational global NWP system. CAS/JSC WGNE Research Activities in Atmospheric Oceanic Models, 2 pp., http://www.wcrp-climate. org/WGNE/BlueBook/2014/individual-articles/01_Yamashita_ Koji_WGNE_BB2014_MISR_yamashita_final.pdf.

Zhu, Y., and R. Gelaro, 2008: Observation sensitivity calculations using the adjoint of the Gridpoint Statistical Interpolation (GSI) analysis system. Mon. Wea. Rev., 136, 335-351, https:// doi.org/10.1175/MWR3525.1. 